\title{
IMPACTO DE LAS MEDIDAS ADMINISTRATIVAS ANTE EL COVID-19 EN LAS DINÁMICAS SOCIOCULTURALES EN CUETZALAN DEL PROGRESO, PUEBLA
}

\author{
Impact of administrative responses due to COVID-19 on \\ sociocultural dynamics in Cuetzalan del Progreso, Puebla
}

\section{Jazmín Arias-Hernández}

Universidad Autónoma de San Luis Potosí, México.

ORCID: 0000-0002-3926-2142

Correo-e: jariash@unal.edu.co

\section{Oscar Reyes Pérez}

Universidad Autónoma de San Luis Potosí, México.

ORCID: 0000-0002-1433-9887

Correo-e osrp@uaslp.mx

Recibido: 22/03/2021 • Aprobado: 18/4/2021

Cómo citar: Arias-Hernández, J., \& Reyes Pérez, O. (2021). Impacto de las medidas administrativas ante el COVID-19 en las dinámicas socioculturales en Cuetzalan del Progreso, Puebla. Ciencia y Sociedad, 46(2), 47-64. DOI: https://doi.org/10.22206/cys.2021. v46i2.pp47-64

\section{Resumen}

La pandemia causada por el COVID-19 ha llevado a tomar diversas medidas que puedan reducir la probabilidad de contagio; sin embargo, e independientemente de su efectividad, se han visto afectados varios sectores sociales y económicos, como el turístico. Esto ha sido particularmente complicado en poblaciones cuya principal actividad económica es el turismo.

Este artículo pretende develar las implicaciones que han tenido las restricciones al turismo en un "pueblo mágico" de México, cuya población es principalmente originaria (masewal) y presenta altos niveles de marginación socioeconómica. A través de una metodología etnográfica basada en entrevistas no estructuradas, observación participante y observación natural, se evaluó la eficiencia e impacto de las decisiones tomadas por el ayuntamiento municipal para evitar los contagios por COVID-19 en Cuetzalan del Progreso.

Los resultados muestran que las medidas no se cumplieron completamente debido a que las decisiones no se tomaron con la participación de los habitantes ni se tuvieron en consideración sus carencias económicas y su alta dependencia del turismo como medio de subsistencia. Por
Abstract

The pandemic caused by COVID-19 triggered several policies to minimize infection. However, independently of their effectiveness, several social and economic sectors such as the touristic one, have been greatly affected by these policies. This has been even more evident in towns where tourism is the main economic activity.

This article discusses the consequences of tourism restrictions in a pueblo mágico of Mexico, where the population is mainly indigenous (masewal) and faces high socioeconomic marginalization. Through an ethnographic methodology based on unstructured interviews, participant observation, and naturalistic observation, the efficiency and impact of municipal town hall decisions to prevent contagious by COVID-19 in Cuetzalan del Progreso was evaluated.

The results show that the policies did not achieve full compliance due to inhabitants not participating in the policy-making process. Policies' ineffectiveness is explained by its misalignment with inhabitants' economic needs and by ignoring their high dependence on tourism for their livelihood. Restrictions disproportionately affected the poorest people who depend on their daily labor for income. Despite this situation, the municipality of Cuetzalan del 
otro lado, las restricciones afectaron principalmente la economía de las personas más pobres, quienes dependen de sus labores diarias para obtener ingresos. A pesar de la situación, el municipio de Cuetzalan del Progreso se caracteriza por su resiliencia territorial, lo que se reflejó en el diseño de estrategias comunitarias para el fortalecimiento social.

Palabras clave: pandemia; turismo; población indígena; dinámica cultural; política económica

\section{Introducción}

\section{Libre determinación, autonomía y autogobierno}

La libre determinación de los pueblos originarios se fundamenta en la igualdad de trato, al constituirse en su derecho colectivo para determinar de manera libre su condición política y desarrollo económico, social y cultura; dentro de la libre determinación se encuentra la autonomía o autogobierno, que se relaciona con su derecho de toma de decisiones con respecto a asuntos internos y externos, al igual que con su facultad para encontrar los medios que les permitan financiar sus funciones autónomas (International Work Group for Indigenous Affairs -IWGIA-, 2019). Entre los aspectos centrales que posibilitan la libre determinación de los pueblos originarios se encuentran el control sobre sus territorios, la realización de derechos culturales (usos y costumbres, lenguas y conocimientos) (TauliCorpuz, 2020) y las relaciones más equilibradas que sostienen con la naturaleza, a través de una filosofía del "buen vivir" (Mosonyi, 2021) (yeknemellis en náhuat $\left.{ }^{1}\right)$.

Ahora bien, aunque hay una amplia diversidad en los modelos de autonomía y se han dado avances en materia de legislación en algunos países, organizaciones como las Naciones Unidas y la Comisión Interamericana de Derechos Humanos han

\footnotetext{
${ }^{1}$ Variante del náhuatl de la región de Cuetzalan, en esta no se emplea la 1 (ele) final (González Álvarez, 2020).
}

Progreso demonstrated territorial resilience by designing communitarian strategies for social strengthening during the COVID-19 pandemic.

Keywords: pandemics; tourism; indigenous peoples; cultural dynamics; economics policy

expresado que en la práctica aún es bajo el reconocimiento de derechos a los pueblos originarios, estos enfrentan oposición e incluso violencia por parte de gobiernos, acuerdos comerciales internacionales, empresas privadas, medios de comunicación e iglesias (IWGIA, 2019). Así, muchas veces "sólo puede ejercerse, en el mejor de los casos, lo que podría denominarse una 'libre determinación fragmentada”" (Tauli-Corpuz, 2020, p. 14).

Por tanto, si bien el reconocimiento de los pueblos originarios a la libre determinación posibilitaría avances significativos en términos de derechos humanos, equidad, democratización, inclusividad y legitimidad del mismo Estado (Tauli-Corpuz, 2020), la realidad es que aún falta mucho por lograr y por ello, ante las trabas a sus garantías, pobladores y pobladoras originarias se han organizado y en pie de lucha, trabajan para lograr la restitución de derechos socavados históricamente. Este proceso de resistencia ha significado costos económicos y humanos, y aunque estos últimos son los más difíciles de cuantificar, se evidencian en estigmatizaciones, presiones y pérdida de vidas. Aun así, la resistencia y organización se mantiene, ya que de otra forma no habría sido posible persistir tras más de 500 años de aniquilación física y simbólica.

A pesar de los obstáculos, la movilización de las poblaciones originarias se acrecienta, es más sólida y estructurada, haciendo más fuerte su clamor sobre el cumplimiento de acuerdos, pactos y, en suma, la garantía de sus derechos. Es importante destacar 
además, que los mecanismos de movilización adelantados por los pueblos originarios contribuyen de manera simbólica al cambio de imaginarios, evidenciando la posibilidad de construir redes contrahegemónicas que rompen con los statu quo, jerarquías y relaciones de dominación (Mosonyi, 2021).

Es claro que la contingencia decretada por el COVID-19 presiona a los entes administrativos a decretar medidas oportunas que procuren la salvaguarda de las poblaciones humanas; sin embargo, es fundamental no perder de vista los derechos colectivos de los pueblos originarios para avanzar en la co-construcción de estrategias que, en efecto, respondan con prontitud a las necesidades sanitarias pero que, además, sean culturalmente adecuadas y apropiadas por la comunidad.

\section{Resiliencia territorial comunitaria}

En el contexto de las luchas de los pueblos originarios, su capacidad de resiliencia se expresa a través de estrategias de autoorganización y movilización que les permiten hacer frente a los cambios políticos, económicos y socioculturales en su territorio, que constituye el eje central de su cosmovisión.

Para estos grupos étnicos, el territorio es "un sujeto vivo con conocimientos, señales, sonidos y espacios que resguardan el origen de las plantas y los animales" (Parlamento Andino, 2019, p. 39); por tanto, además de ser un espacio ecológico, también lo es a nivel productivo y cultural (Leff, 2000), ligando la economía, la política, lo social y lo sagrado (Agredo, 2006). Así, para las poblaciones originarias, el territorio no se percibe como un espacio que se posee (o que se debería poseer), sino como aquel que es apropiado a través de las prácticas culturales particulares de cada grupo, es una expresión de su historia y, por lo tanto, es fundamental para sus procesos de aprendizaje individual y colectivos. En consecuencia, el control sobre sus territorios es el corazón de los derechos colectivos enmarcados en la libre determina- ción de los pueblos originarios, así como el motivo central de sus movilizaciones, ya que guardan sus memorias bioculturales y son el espacio en el que construyen su presente.

En este contexto, la resiliencia comunitaria puede ser entendida como la capacidad de los grupos humanos para adaptarse y recuperarse tras un evento disruptivo de origen externo, ya sea un fenómeno natural o una situación de origen antrópico (Maldonado González y González Gaudino, 2013), trabajando de manera colectiva con el uso de recursos comunales, así, incluso podrán enfrentar formas más sutiles de disrupción social como cambios políticos o administrativos locales (Cheshire et al., 2015).

Justamente, la contingencia sanitaria debido al COVID-19, se constituye en un evento que altera significativamente las dinámicas de vida de la población en Cuetzalan del Progreso y más allá de las estrategias implementadas por los distintos órdenes de gobierno, la respuesta y acción comunitaria de la población es determinante en los efectos socioculturales a corto, mediano y largo plazo.

Por tanto, la organización de base como vía para favorecer la cohesión social cobra gran relevancia, dado que se constituye en un elemento que promueve la fortaleza territorial, favoreciendo el establecimiento de interconexiones con otros territorios y haciendo uso de los recursos de manera más responsable (Henriques, 2016).

\section{Identidad territorial como componente del turismo sustentable}

Una comunidad que ha construido y fortalecido su identidad territorial puede generar capital social, que conducirá al empoderamiento (Leff, 2004), entendido como el proceso en el que las personas que han sido tradicional y sistemáticamente marginadas en aspectos político-económicos y socioculturales, van adquiriendo de manera colectiva el control sobre las situaciones que impactan de manera directa 
o indirecta en sus vidas (Contreras, 2000). Es decir, el empoderamiento conduce al poder local que permite la participación incidente de la ciudadanía en la toma de decisiones sobre los territorios. Así, la acción colectiva transforma factores culturales $y$, por lo tanto, las realidades inmediatas.

Una de las vías para orientar los territorios y los pueblos originarios a la resiliencia es pasar de la especialización económica a la diversificación sectorial de sus actividades económicas, insertándolas a fuerzas locales, regionales y de ser posible, globales, con el fin de garantizar un espacio en las dinámicas que trae la modernidad y así evitar ser asimilados, absorbidos o subordinados por empresas, organizaciones y personas ajenas a su cosmovisión. El turismo, bajo una visión de sustentabilidad, representa un complemento importante en comunidades cuyas actividades principales son las agropecuarias y comerciales, toda vez que coadyuva al fortalecimiento de la identidad territorial, promueve el empoderamiento, contribuye a la resiliencia e idealmente, a la libre determinación de los pueblos originarios.

El turismo sostenible es la aspiración a la que toda práctica turística debe orientarse, dado que el ecoturismo y hasta las formas más tradicionales de esta actividad han dejado impactos físicos, sociales y culturales, que suelen poner en duda si sus beneficios económicos justifican su existencia. $\mathrm{Al}$ respecto, se ha documentado la transformación de espacios rurales a urbanos, el establecimiento de relaciones de poder que privilegian a determinados sectores sociales, la promoción de la estratificación laboral, la modificación de costumbres, el debilitamiento de las tradiciones e incluso, la destrucción, robo y vandalismo de estructuras patrimoniales (Morales Morales, 2006). Así, la falta de planeación en el turismo ha conducido en muchos casos a una estrategia económica excluyente, en la que, en ocasiones, se ejercen derechos privados sobre territorios de uso público (Orozco Alvarado y Núnezz Martínez, 2013).
Estas condiciones suelen ser evidentes en los territorios de poblaciones originarias, en donde la "inclusión" por parte de los empresarios mestizos suele remitirse a la contratación de dichos grupos poblacionales como meseros y aseadores. Por otro lado, en términos biofísicos, el territorio sufre deterioro, la biodiversidad se estresa o maltrata y se afecta la calidad de suelo y agua; todo esto se agudiza cuando no existe normativa, regulación o seguimiento claro con respecto a capacidades de carga.

Por lo tanto, el turismo sostenible de identidad persigue que las actividades se realicen bajo principios de conservación ecosistémica, respeto cultural, inclusión, equidad y oportunidad; adicionalmente, representa la posibilidad de conjugar el patrimonio cultural-histórico con el desarrollo económico de las comunidades, ya que son ellas quienes pueden transmitir en su justa dimensión, el valor cultural del territorio, pues es parte de su vida y sus realidades (Alcívar y Bravo, 2017); es decir, no es un producto fabricado para consumo turístico.

En este contexto, varias comunidades con fuerte presencia o predominio de pueblos originarios y en donde se han establecido las bases de un turismo sustentable, tensores como la pandemia causada por el virus SARS-CoV-2, han ejercido un impacto que debe ser mensurado, pues los efectos se prolongarán por un tiempo aún indeterminado.

\section{Cuetzalan del Progreso}

Situado en la porción noreste del estado de Puebla, Cuetzalan del Progreso es uno de los 217 municipios que integran a esta entidad federativa (figura 1). Por su localización en la Sierra Madre Oriental, propiamente en las estribaciones orientadas hacia la llanura costera del Golfo de México, recibe una importante influencia marítima, situación que le confiere condiciones climáticas semicálidas con temperaturas medias anuales que oscilan entre los $18^{\circ} \mathrm{C}$ y $22^{\circ} \mathrm{C}$ y precipitaciones en la mayor parte del año, siendo abundantes en verano. Además, al existir un predo- 
minio de sustratos rocosos sedimentarios de origen marino que datan del mesozoico, así como condiciones de humedad y temperatura que propician procesos kársticos, se han desarrollado numerosas grutas. Por otra parte, debido a las condiciones topo- gráficas, edafológicas, hidrológicas y climáticas en el municipio, las cubiertas vegetales primarias consistieron en bosque mesófilo de montaña y coníferas latifoliadas, de las que solo quedan algunos relictos (Instituto de Geografía -UNAM, 1992, 2007).

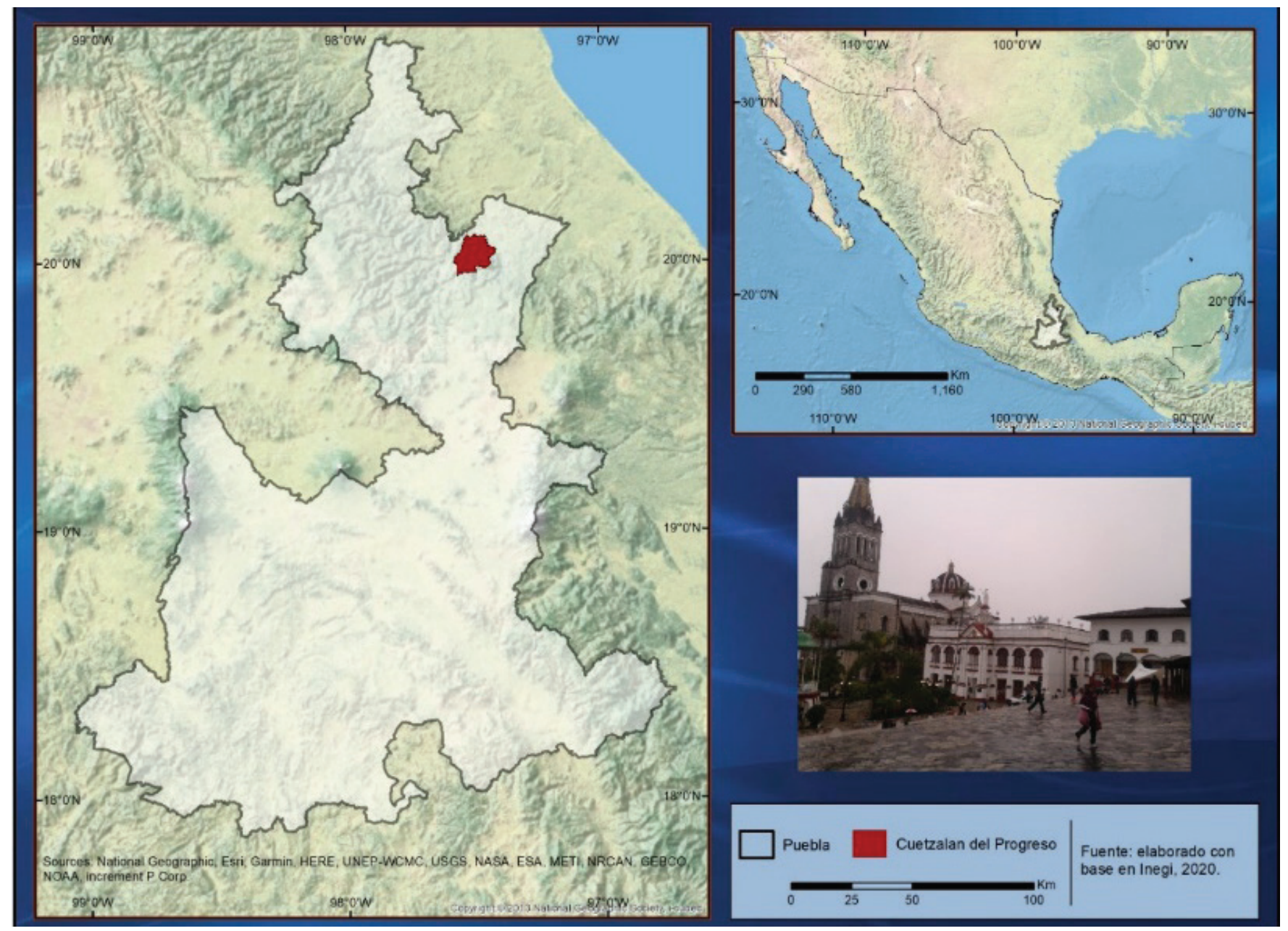

Figura 1. Ubicación del municipio de Cuetzalan del Progreso, Puebla

Nota: elaboración propia, información de Instituto Nacional de Estadística y Geografía (2020b).

La Sierra Norte de Puebla o el antiguo Totonacapan del área cultural conocida como Mesoamérica, abarca a varios municipios del estado de Puebla, entre ellos, a Cuetzalan del Progreso. El poblamiento de este territorio se remonta al ańo 750 a.C, momento a partir del cual se asentaron personas de habla totonaca, otomí, tepehua y náhuat, siendo estos últimos los que en la actualidad predominan. Los habitantes de esta región poblana, desde una perspectiva de identidad territorial se definen como "serranos", "nacos" o "masewalmej", en clara distinción de los mestizos a quienes conciben como "los de razón" o "koyomej" (Báez, 2004).

Debido a las condiciones topográficas de su territorio, Cuetzalan del Progreso, hasta mediados del siglo XIx había logrado que fuese marginal la presencia de "forasteros", pero a partir de la introducción 
del cultivo del café, inmigrantes europeos comenzaron a establecer su primacía en lo económico (Báez, 2004). En la actualidad, en este municipio, las expresiones culturales de los pueblos originarios masewal y tutunakú (figuras $2 \mathrm{~A}$ y $2 \mathrm{~B}$ ) y la arquitectura hispana (figuras $2 \mathrm{C}, 2 \mathrm{D}, 2 \mathrm{E}$ y $2 \mathrm{~F}$ ) son parte de su patrimonio turístico.

Figura 2. Patrimonio cultural de Cuetzalan del Progreso

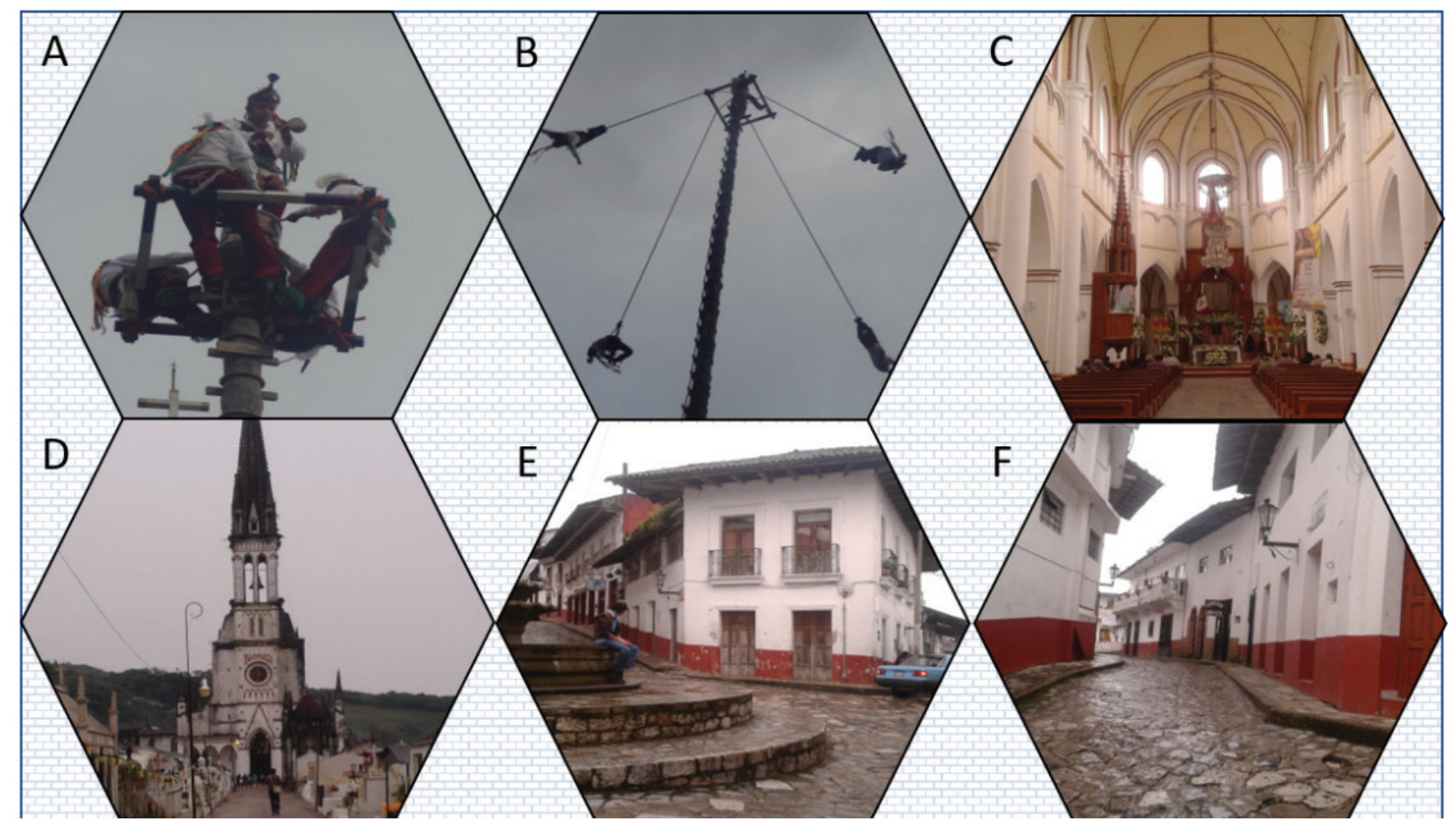

Nota: trabajos de campo, 2012-2019.

La diversidad de atractivos culturales y arquitectónicos, entre los que destacan sus danzas, fiestas religiosas, ferias y festividades, arquitectura vernácula, junto con la belleza escénica de sus paisajes naturales, ha permitido el desarrollo de diferentes prácticas de ocio y recreación, entre ellas, actividades de aventura, turismo rural y arqueológico (Gobierno del Estado de Puebla, 2016). En este contexto, la cabecera municipal de Cuetzalan del Progreso, desde 2002, recibió la distinción de pueblo mágico (García González y López Guevara, 2018), reconociendo a su vez, la vocación turística de la población (H. Ayuntamiento de Cuetzalan del Progreso Puebla, 2018). Esta es una categoría otorgada por la Secretaría de Turismo a pueblos que cuentan con características identitarias (conservación de herencia histórica, cultural y natural) que expresan a través de patrimonio material e inmaterial y resultan atractivas a turistas locales y extranjeros (Bellota, 2017).

El sentirse masewalmej ha permitido que la población del municipio de Cuetzalan del Progreso se organice y trabaje con metas comunes. De hecho, desde 2010, con la promulgación del Programa de Ordenamiento Territorial Integral del municipio, cuetzaltecas y cuetzaltecos se han apropiado de este instrumento de planeación para decidir el estado y futuro del territorio, de tal manera que se han opuesto a los intereses de élites que pretenden esta- 
blecer megaproyectos y modificar las condiciones de vida del municipio; en contraparte, bajo una visión de sustentabilidad, promueven el turismo, pues forma parte de las estrategias ecológicas en las Unidades de Gestión Ambiental definidas en este programa (Gobierno del Estado de Puebla, 2010).

Con respecto a la caracterización económica, según la Encuesta Intercensal 2015 y el Censo Económico de 2014, la proporción de la población que laboraba en el sector primario era del $44.1 \%$ (principalmente en actividades agropecuarias), le seguía en importancia el sector terciario con el $38 \%$, siendo en este caso los servicios los que absorbieron el mayor número de trabajadores y por último, estaba el sector secundario con el $17.5 \%$ (CEIGEP, 2021) . En cuanto a la información del Censo Económico 2019, la producción bruta total de este municipio fue de $\$ 299.5$ millones de pesos, a estas actividades asociadas directamente con el turismo aportaron $\$ 70.5$ millones de pesos, aproximadamente el $23.5 \%$ (INEGI, 2020a).

En relación con la afectación que tuvo el virus SARS-CoV-2 (COVID-19) durante 2020, los datos proporcionados por la Secretaría de Salud revelan que en el municipio de Cuetzalan del Progreso hubo 50 casos, de los cuales el $62 \%$ correspondió a mujeres, el $38 \%$ a hombres y el $32 \%$ se presentó en población originaria. Por otro lado, se registraron cinco decesos en población originaria de los nueve presentados (Secretaría de Salud, 2020).

Adicionalmente, la organización social y las dinámicas socioculturales características del territorio se trastocaron por las medidas implementadas por los diferentes niveles de gobierno, en particular las que fueron formuladas por las autoridades municipales, quienes tomaron la decisión de prohibir la entrada a turistas por cerca de seis meses y cerrar los accesos a los sitios turísticos. Por lo anterior, este trabajo se enfoca en el análisis de estas medidas y sus efectos inmediatos para el municipio de Cuetzalan del Progreso.

\section{Metodología}

La investigación se realizó bajo un enfoque cualitativo, con base en una tipología de carácter descriptivo y siguiendo métodos etnográficos. Para tal fin, se consultaron los comunicados oficiales publicados por el ayuntamiento municipal a través de su página oficial de Facebook, entre marzo y noviembre de 2020; en estos documentos se encontró información sobre las medidas adoptadas para atender la emergencia sanitaria ocasionada por el COVID-19 y de esta manera, pudo identificarse la incidencia directa e indirecta en los servicios asociados al turismo.

Asimismo, entre los meses de abril y noviembre de 2020, se realizó observación participante y observación natural de las actividades y dinámicas socioculturales asociadas al turismo, asistiendo a celebraciones, rituales y fiestas tradicionales de la comunidad, y visitando sitios icónicos particularmente en las tres localidades que concentran la mayor cantidad de atractivos turísticos, ciudad de Cuetzalan, San Miguel Tzinacapan, San Andrés Tzicuilan y Yohualichan.

A la par, se aplicaron 20 entrevistas no estructuradas a habitantes del municipio de Cuetzalan del Progreso que tienen relación directa o indirecta con la prestación de servicios asociados al turismo (artesanas, comerciantes de cafeterías, tenderos, prestadores de servicio de hospedaje, guías turísticos, prestadores de servicio de actividades de aventura, danzantes), en las que se dialogó sobre la efectividad de las medidas implementadas por la administración municipal para hacer frente a la pandemia de COVID-19 y su impacto en las dinámicas socioculturales.

La selección de las personas entrevistadas se realizó a partir de una identificación realizada durante las observaciones participantes y naturales. Cabe aclarar que, con el fin de que estas personas se expresaran libremente y sin temor a represalias, se les garantizó su anonimato. 


\section{Medidas adoptadas por el ayuntamiento}

El 16 de marzo de 2020 se dio la primera acción de la administración municipal relacionada con el COVID-19 con la publicación de una infografía básica, tanto en español como en náhuat (figura 3).
Dos días después se informó que estarían cancelados hasta el 20 de abril de 2020 todos los eventos públicos cívicos, sociales, deportivos y culturales; igualmente se mencionó que esta medida podría extenderse según indicaciones de las autoridades federales o estatales.

Figura 3. Primera infografía de Cuetzalan del Progreso sobre COVID-19 en español y náhuatl

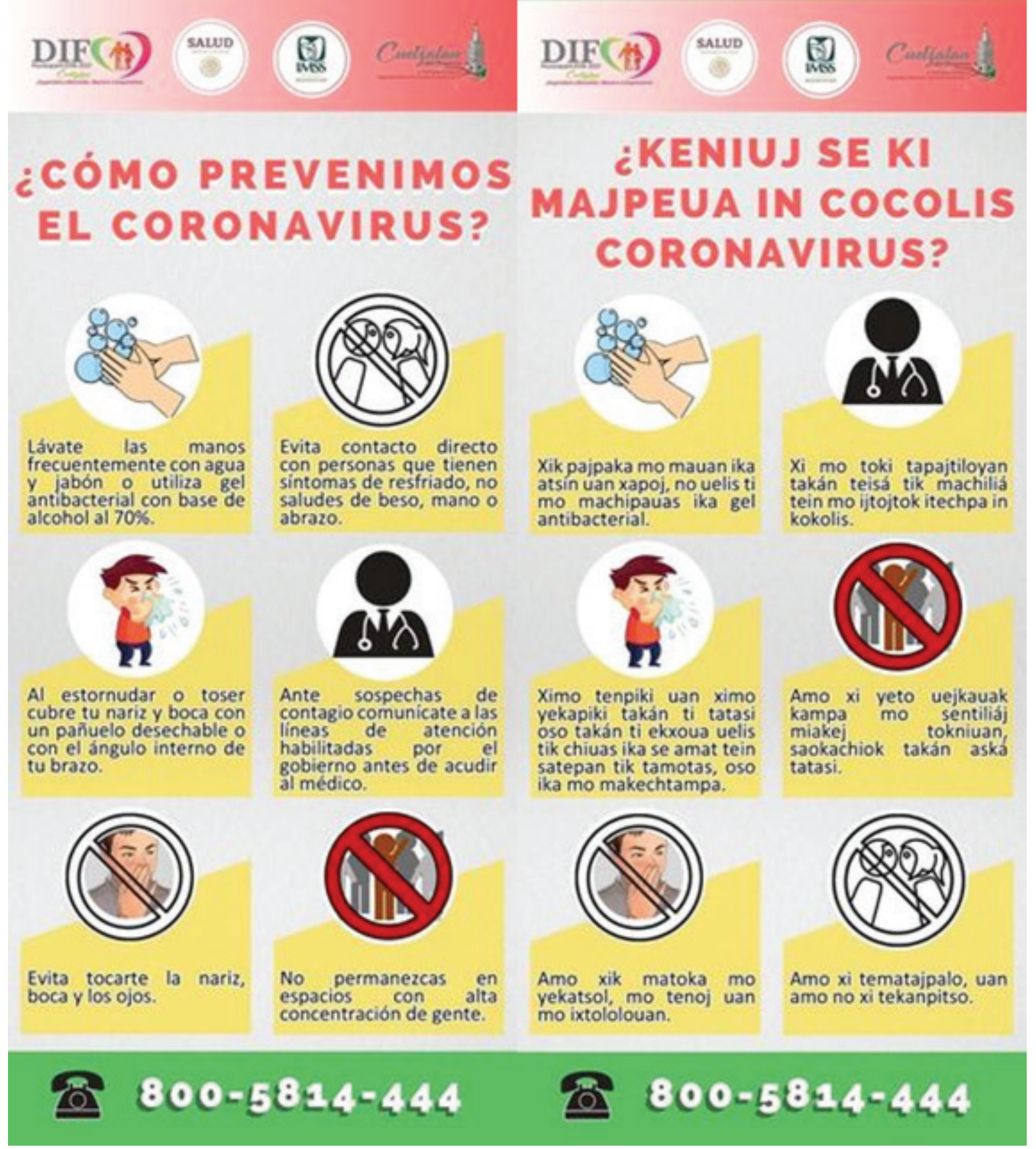

Nota: fuente, H. Ayuntamiento de Cuetzalan del Progreso Puebla (2020). 
El 20 de marzo de 2020, el ayuntamiento municipal publicó un boletín informativo en el que explicó las fases de propagación del virus, notificó la suspensión de clases a partir de las determinaciones de la Secretaría de Educación Pública Estatal y el Gobierno de México e indicó que no se implementarían restricciones para las actividades comerciales y turísticas, salvo la medida de distanciamiento social.

Sin embargo, a partir del 1 de abril de 2020, se dieron a conocer las decisiones que tuvieron incidencia en las actividades de interés turístico:

- Suspensión de actividades productivas no esenciales.

- Prohibición de actividades que congreguen más de cincuenta personas.

- Cierre de plazas, parques, canchas, auditorios y otros espacios recreativos.

- Cancelación de fiestas patronales, mayordomías, fiestas particulares, eventos sociales y turísticos.

- Cierre de todos los atractivos turísticos (grutas, ríos y cascadas, entre otros).

- Restricción de ingreso a foráneos que presenten síntomas de enfermedades respiratorias.

- Prohibición de ventas en espacio público, a excepción de los mercados (tianguis) realizados los jueves y domingos en la vía principal de la cabecera municipal; sin embargo, en estos únicamente quedó permitida la venta de alimentos y bebidas.

Posteriormente, el 8 de abril de 2020, se incluyeron otras medidas:

- Limitación de los servicios de hospedaje al $15 \%$ de su capacidad y únicamente para foráneos que se hospeden por motivos humanitarios o laborales. Se prohibió el alojamiento a turistas y las reservaciones durante la contingencia.

- Suspensión de los tianguis realizados los jueves y domingos en la vía principal de la cabecera municipal.

Dando alcance a la suspensión de tianguis, el 9 de abril de 2020 se publicó el oficio SG/0032/IV/2020 en el que se hizo prohibición explícita para establecer puestos de venta en plazas, explanadas y vía pública, so pena de disposición fiscal municipal y el retiro de los artículos mediante el uso de la fuerza pública. Ese mismo día, se notificó que a partir de las 6:00 horas del 10 de abril de 2020, no se permitiría el ingreso a turistas, instando a regresar a su lugar de origen o permanecer en aislamiento durante catorce días.

Debido al registro del primer caso de COVID-19 en el municipio, el 19 de abril de 2020, se tomaron medidas más restrictivas, como la reducción a máximo diez personas para la celebración de eventos, reducción del cupo para transporte público al $50 \%$ de su capacidad y prohibición de venta de bebidas alcohólicas abiertas, al igual que su consumo en el lugar de venta, fuera de ellos o en vía pública.

Luego, el 2 de mayo de 2020, se notificó la adopción del Decreto del Ejecutivo del Estado en el que se suspendió la venta de alimentos preparados y bebidas no alcohólicas para consumo en el establecimiento; únicamente quedó permitida su venta para entrega a domicilio o para llevar.

Las medidas restrictivas comenzaron a atenuarse a partir de la emisión del Decreto del Ejecutivo del Estado del 7 de agosto de 2020, pues se establecieron lineamientos para la apertura gradual y responsable de las actividades económicas. Para tal fin, el ayuntamiento municipal dio a conocer los términos para proceder a una reactivación económica escalonada, que comenzaría a partir del 23 de agosto de 2020 bajo el siguiente esquema: 
- Los domingos únicamente podrían prestar sus servicios los establecimientos comerciales esenciales.

- Los domingos, los establecimientos de alimentos preparados solo podrían ofrecer sus servicios a domicilio o para llevar.

- Cierre o suspensión de salones de eventos, bares, cantinas, balnearios y eventos deportivos y culturales.

- Prohibición para la realización de eventos de más de diez personas.

- Servicio de hospedaje únicamente de lunes a sábado, con aforo de hasta el $30 \%$, bajo previa reserva y registro en el sitio web del ayuntamiento municipal. Limitación en el uso de áreas comunes y prohibición al uso de piscinas.

- Actividades turísticas ofrecidas por guías y operadores turísticos, permitidas de lunes a sábado, con aforo reducido, bajo previa reserva y registro en el sitio web del ayuntamiento municipal. Prohibición de oferta de servicios en la vía pública.

- Prohibición de actividades ecoturísticas a población adulta mayor, infantes menores de 10 años, mujeres embarazadas y personas en situación de vulnerabilidad, durante nivel de riesgo de contagio muy alto y alto.

- Prohibición de recorridos turísticos en transporte público. El uso de transporte privado estaría limitado al $50 \%$ de su capacidad.

- El aforo de los sitios turísticos estaría limitado al $30 \%$ de su capacidad, a excepción de los domingos, que deberían estar cerrados al público.

- Los atractivos turísticos en los que no pueda hacerse control de acceso deberían permanecer cerrados.
- Las operadoras turísticas foráneas deberían seguir los lineamientos generales y, adicionalmente, registrar previamente su visita con la regiduría de turismo y contratar los servicios de un guía, anfitrión u operadora turística.

- Los turistas deberían firmar una carta de corresponsabilidad al ingresar a los hoteles, en donde se comprometiesen a cumplir las disposiciones establecidas por las autoridades sanitarias y municipales, con respecto a las medidas adoptadas frente al COVID-19.

- Se incluyó el lunes como día de mercado en el auditorio municipal, priorizando a los comerciantes que no cuentan con establecimiento fijo.

- El mercado de artesanías podría ofrecer servicio de lunes a sábado. Prohibición de venta en vía pública.

A partir del 10 de octubre de 2020 hubo mayor apertura, tal y como puede apreciarse a través de las siguientes medidas:

- Los establecimientos comerciales, incluyendo servicios turísticos, establecimientos de alimentos preparados, hospedaje y mercado de artesanías, podrían operar todos los días de la semana.

- Apertura de canchas comunitarias y autorización para realizar deportes al aire libre. Se excluyó la celebración de torneos.

- Reinicio de tianguis los jueves, con aforo reducido y horario limitado.

\section{Impactos en la organización social y dinámica económica}

Los efectos de la pandemia por COVID-19 en la estructura social y económica de Cuetzalan del Progreso están lejos de cuantificarse para el mediano y largo plazo. Sin embargo, durante la estancia en este municipio antes de la existencia de una vacuna, 
se pudieron dimensionar los daños ocasionados y la forma en que los habitantes de este municipio pudieron enfrentarlos.

\section{Hospedaje y sitios turísticos}

Los puestos de control instalados para la restricción de turistas al municipio, únicamente limitó la entrada a vehículos particulares, a cuyos ocupantes solicitaban documentación que comprobara que su residencia era Cuetzalan del Progreso, se tomaba la temperatura, se suministraba gel antibacterial y se reiteraba la información referente al cierre de atractivos turísticos. Sin embargo, no se realizó este control a los autobuses que ingresaban o salían del municipio, razón por la cual personas foráneas siguieron ingresando al municipio, pero con la imposibilidad de hospedarse en hoteles y visitar los sitios usualmente frecuentados por turistas: grutas, ríos, cascadas, jardín botánico y zona arqueológica.

Si bien la actividad de hoteles y hostales se limitó considerablemente, la afectación a la economía local no fue tan significativa, ya que la gran mayoría de estos hospedajes son propiedad de personas ajenas al municipio, que apenas emplean a algunas locales para servicios varios. $\mathrm{Al}$ respecto, una persona de la cabecera municipal comentó lo siguiente:

"sí, la mayoría son de afuera, tan sólo tú recorres la calle principal y son pocos los dueños que son de acá... hay mucho comercio que no es de acá y lo mismo pasa con las calles que están alrededor... la economía no se mueve local porque todo ese dinero que generan, pues sí deja un poco porque sus empleados son de acá, pero ¿qué te gusta?, o sea, toda la demás utilidad la mueven al lugar de donde son, o sea, realmente Cuetzalan en productividad no te queda".

Por otro lado, dentro del municipio se encuentran diferentes opciones de hospedaje además de los hoteles y hostales, tales como Airbnb y casas particulares; en el caso de estas dos últimas, el control para verificar que no se realizaba alojamiento es virtualmente imposible, por lo que unas pocas personas podían llegar a alojarse. En este sentido, la persona responsable de un hotel externó:

"acá cumplimos con el cierre, el ayuntamiento dio la orden y no se permite el hospedaje, pero con esos Airbnb que ni pagan impuestos no se sabe, nadie los obliga".

Sin embargo, ante el cierre de los sitios turísticos, la afluencia de turistas fue disminuyendo de forma paulatina a partir del mes de abril, especialmente debido a la cancelación de fiestas, ferias y celebraciones. Esto provocó un cese de actividades de cerca de cuatro meses y medio para los guías locales, afectando seriamente sus ingresos económicos, ya que dependen exclusivamente del turismo como fuente de sustento. Sobre esta situación, uno de los entrevistados refirió lo siguiente:

"el presidente no le dio permiso al dueño (del predio en el que se encuentra el lugar turístico) y por eso la gente no podía venir, estaba cerrado y tuvimos muchos problemas... nosotros nos apoyamos con eso".

Aun así, puede considerarse como aspecto positivo una de las medidas que se implementó a partir de agosto, en la que se obliga a las empresas turísticas foráneas a contratar los servicios de guías locales como estrategia para recuperar la economía local, y puede decirse que como beneficio adicional aportó elementos para la consolidación del turismo sostenible de identidad al favorecer el respeto por los aspectos simbólicos del territorio. Así, al otorgarse un mayor control local del turismo, se favorece la planificación y las buenas prácticas de la actividad en el municipio en procura de la conservación de la riqueza del territorio (de Esteban Curiel y Antonovica, 2018), toda vez que se vinculan las políticas de patrimonio (y turismo) cultural con el bienestar de los habitantes locales (Bui et al., 2020). 


\section{Fiestas, ferias y celebraciones}

Por mandato municipal, desde abril todas las festividades del municipio se cancelaron y la Plaza Celestino Gasca, el sitio más importante de reunión y celebración, fue cerrada. Así, las celebraciones tradicionales de Semana Santa y la Feria del café y del huipil, que convocan el mayor número de turistas en el municipio todos los años, no fueron realizadas, afectando a todo el sector de servicios asociados al turismo: hospedajes, fondas, restaurantes, cafeterías, guías turísticos, lugares turísticos, artesanas y artesanos. De hecho, las reservas realizadas para las fechas más importantes del turismo en Cuetzalan del Progreso fueron canceladas.

En Semana Santa no se adelantaron las actividades acostumbradas, como el tradicional ritual de la danza de los voladores y las eucaristías, no hubo presencia relevante de turistas y la circulación por el centro del municipio fue escasa. En tanto que para la fiesta patronal de la cabecera municipal (ciudad de Cuetzalan), durante la cual se realiza la Feria del café y el huipil, únicamente se realizó la entrada de cera a la parroquia de San Francisco de Asís. Y si bien para esta fecha (4 de octubre de 2020) empezó a percibirse la reactivación del turismo, la celebración quedó circunscrita únicamente al aspecto religioso al interior de la iglesia.

Por otro lado, y a pesar de las medidas impuestas por el gobierno municipal, la comunidad de San Miguel Tzinacapan decidió realizar su fiesta patronal en honor a San Miguel Arcángel, pues tal como lo manifiestan los sanmigueleños, este no es un festival que se realice para atraer turistas, es una celebración de los lugareños para honrar a su patrón. Por tal razón, la fiesta se realizó igual que otros años, con la salvedad de que en esta ocasión no se permitió la asistencia de foráneos. "todo es ritual, desde la puesta del palo... todo es para dar agradecimiento a la madre tierra, para que proteja a los danzantes... todos los danzantes son originarios",

"nosotros le dijimos al presidente (municipal) que hacíamos nuestra fiesta porque es para nuestro patrón, pero que iba a estar cerrada al turista”.

Tras la "desobediencia" de la comunidad de Tzinacapan, subyacen motivos trascendentes de su cosmovisión como pueblo masewal, pues durante esta festividad se llevan a cabo cerca de una docena de danzas prehispánicas, entra las que destaca la Danza de los Voladores (koujpapataninij en náhuat), que relaciona el tiempo y el espacio; a través de ella se pide agua hacia el subsuelo ofrendando a la tierra y a los cuatro puntos cardinales, que representan la vida (oriente), el reposo de los ancestros (occidente), la cabeza del territorio (sur) y los vientos y lluvias (norte) (González Álvarez, 2018).

Además, en cuanto a la intencionalidad de la fiesta, las medidas adoptadas frente a la contingencia por el COVID-19, la comunidad de Tzinacapan se vio liberada del turismo depredador, que acude a ver sus danzas y celebraciones como un producto de consumo, sin conocimiento o respeto por los rituales, situación que ha llevado a enfrentamientos y conflictos entre masewalmej (población masewal) y mestizos.

\section{Establecimientos comerciales}

Aunque los lineamientos del ayuntamiento municipal solo permitían el funcionamiento de establecimientos esenciales y limitaban los días en los que podrían hacerlo, la gran mayoría de comerciantes optó por mantener abiertos sus comercios, con 
pocas restricciones a los compradores. Únicamente los expendios de bebidas alcohólicas (tipo cantina, bar o discoteca) cumplieron la medida, pues eran sujeto de controles permanentes por integrantes del gobierno municipal. Con respecto a la medida que prohibía que los domingos se vendieran alimentos preparados para consumo en los establecimientos, los comerciantes de cafeterías y restaurantes manifestaron la baja eficiencia para reducir la probabilidad de contagio por COVID-19:

"sí vienen del ayuntamiento a verificar que no tengamos personas dentro del local, pero no sirve nada, el sábado es el día de mayor movimiento, no el domingo".

\section{Sector artesanal}

Aunque las artesanías no son consideradas una actividad esencial y, por lo tanto, con las medidas restrictivas no debía funcionar el mercado artesanal y fueron prohibidas las ventas en vía pública, en la práctica esta medida no fue acatada debido a las características particulares de la población, especialmente femenina del municipio. Como se ha enunciado, el territorio es habitado principalmente por población originaria con niveles altos y muy altos de marginación socioeconómica y la principal actividad económica de las mujeres es la artesanía y si bien pueden encontrarse hombres artesanos, es una actividad desarrollada por ellas.

Bajo este escenario, las artesanas que se desplazan desde sus comunidades hasta la cabecera municipal para vender sus productos en vía pública continuaron haciéndolo ininterrumpidamente, ante la necesidad de conseguir el sustento para sus familias $y$, de hecho, ante la escasa presencia de potenciales compradoras y compradores en la plaza, empezaron a recorrer toda la ciudad de Cuetzalan, por lo que era frecuente verlas en calles, andenes, cafeterías y restaurantes.

"con esta situación que no les dan permiso y todo, lo que hace esa gente (artesanas y artesanos que no tienen lugar fijo de venta) es agarrar todas las callecitas que están más aledañas, no tan céntricas y van rogando casa por casa”.

Con respecto al mercado artesanal, si bien algunos locales se cerraron durante el mes de abril, otros apenas lo hicieron durante algunas horas y los demás mantuvieron su actividad regular; ya en el mes de mayo, fue incrementándose paulatinamente la apertura de locales. Sin embargo, uno de los efectos del descenso en ventas fue el cierre definitivo de locales que algunas artesanas habían rentado en otros puntos de la cabecera municipal:

"yo aquí rentaba también por aquí arriba y ahora con lo de la pandemia, pues tuvimos que salir porque no podíamos pagar ya más".

A pesar de continuar con su actividad económica, la ausencia de turistas afectó seriamente los ingresos percibidos por artesanías, razón por la cual se diversificaron los bienes producidos ante las nuevas necesidades impuestas por la pandemia de COVID-19, creando cubrebocas artesanales; así, fabricaron un producto de consumo general, pero con uno de los sellos culturales distintivos de la población cuetzalteca, sus bordados (figura 4). Igualmente, algunos grupos de artesanas se organizaron para vender de manera directa sus productos a través de plataformas tecnológicas:

"como no podemos salir a otros sitios y las personas que nos compran en cantidad no pueden entrar, mi hija nos está ayudando a ofrecer las artesanías por internet y sí, se han vendido cositas". 
Figura 4. Cubrebocas artesanales cuetzaltecos

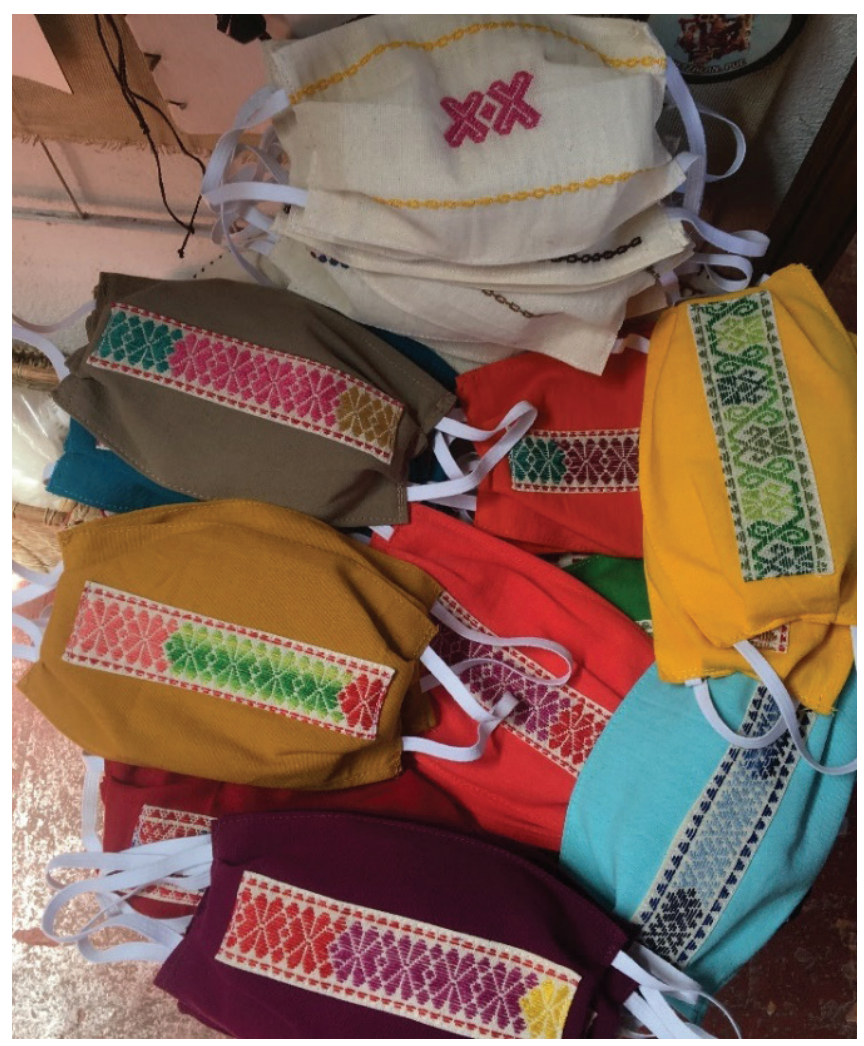

Nota: trabajo de campo 2020.

Esta diversificación de bienes y estrategias de comercialización es ejemplo de una de las estrategias de resiliencia rural importantes para mejorar la seguridad económica (Brown y Schafft, 2019) ante una situación de crisis. Aunque no puede afirmarse que fue un éxito total, constituyó un mecanismo que le permitió a las artesanas y artesanos atender sus necesidades básicas.

\section{Mercado tradicional}

La suspensión del tianguis fue una de las medidas de mayor incidencia, dado que una gran cantidad de productores de las comunidades del municipio y de municipios aledaños suelen establecerse en los espacios destinados de la vía pública para comercializar diversos bienes. Una vez se suspendió el tianguis el 8 de abril de 2020, estos productores perdieron su punto fijo de venta, y aunque algunos produc- tores de las comunidades cuetzaltecas fueron reubicados temporalmente en el mercado permanente para garantizar el abasto de productos alimentarios a la cabecera municipal, lo cierto es que enfrentaron condiciones que favorecían el riesgo de contagio:

"solamente nos dejaron a unos pocos y se les agradece el traslado, pero hay poco espacio y la gente se amontona... además en el mercado no hay ventilación".

Ello llevó a que el 19 de abril de 2020 se destinara el auditorio municipal como espacio temporal para la realización de los tianguis de jueves y domingo, manteniendo distanciamiento social entre los puestos de venta. Esto, por supuesto, limitó considerablemente la cantidad de productores que podrían establecerse allí; fue el mismo ayuntamiento, bajo criterios propios, el que seleccionó a los productores del municipio que tendrían un lugar en este espacio.

A pesar de las restricciones, algunos productores de otros municipios se desplazaron a Cuetzalan del Progreso para ofrecer sus productos, pero al llegar al puesto de control del acceso principal al municipio, personal de seguridad pública estatal y municipal bloquearon su ingreso. Como acto de resistencia a la prohibición de venta en vía pública y una forma de defender el derecho para contar con los medios básicos de subsistencia, siempre fue posible observar a pequeños productores de las comunidades que se establecían en alguna calle a vender sus mercancías.

Posteriormente, el 15 de octubre de 2020, con las medidas de reactivación económica, se empezó a organizar nuevamente el tianguis en vía pública, sin restricción de productos a la venta, pero manteniendo el distanciamiento entre los puestos de venta, haciendo que se ocupara una mayor área en los espacios públicos. En la figura 5 pueden evidenciarse los cambios del mercado tradicional. 
Figura 5. A. Tianguis antes de la pandemia, B. Tianguis en auditorio municipal, C. Tianguis en la nueva normalidad

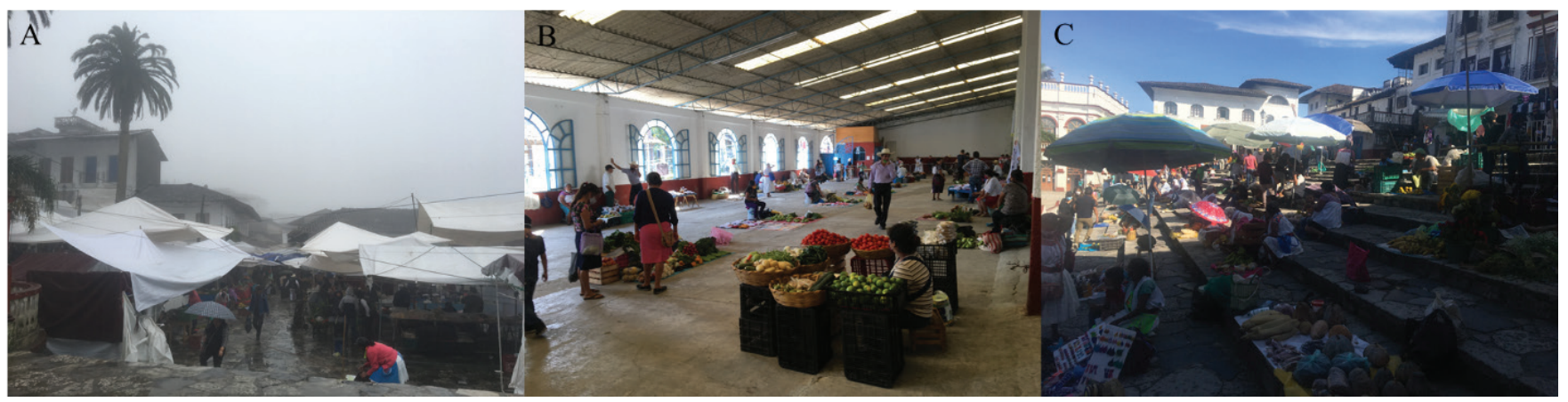

Nota: trabajo de campo 2020.

\section{Apoyo en despensas-mercados}

Teniendo en cuenta las medidas restrictivas para la realización de actividades económicas en el municipio y con el fin de apoyar a los hogares en la consecución de los productos básicos de la canasta familiar, se entregaron despensas suministradas por la Secretaría de Bienestar del Gobierno de México, el Gobierno del Estado de Puebla y el Programa Municipal de Apoyo Alimentario. Sobre esta medida predominó la percepción de que la ayuda llegó a la mayoría de las localidades y que los artículos ayudaron a las familias para enfrentar temporalmente la crisis originada por la pandemia de COVID-19, aunque también surgieron opiniones en torno a un interés político cobijado con una buena acción:

“yo nunca había recibido una despensa del ayuntamiento y estoy muy agradecido con la que recibi”,

"parece campaña política, nos piden la credencial de elector y se toman foto con nosotros".

Por otro lado, la calidad y cantidad de las despensas otorgadas por los tres niveles de gobierno fueron disímiles, siendo las del ayuntamiento las que más se distribuyeron, si bien contenían menos productos y eran más básicas. Ello generó que la distribución de productos no fuera equitativa entre los hogares, lo cual se reflejó en algunos comentarios de la población:

“poco o mucho es una ayuda, lo que debería de haber es igualdad porque a unos les dieron despensa de medio costal y otras fueron sólo una bolsita”.

Adicionalmente, no fue tomada en cuenta la necesidad diferencial de cada núcleo familiar, pues independientemente de cuántas personas hubiese por hogar o su condición socioeconómica, la despensa fue genérica. Esto también generó una situación de inequidad al entregarse la misma despensa a personas con pocas necesidades y a familias con mayores problemas para enfrentar la crisis generada por las medidas de restricción social y disminución de la actividad económica:

"la despensa no alcanza ni para una semana, en la casa somos hartos y eso no lo tienen en cuenta".

Hubo incluso voces que manifestaron corrupción en el proceso de elaboración de las despensas, de las que se extrajeron algunos productos que no llegaron a la población:

“en la lista que sacó DICONSA -red de abasto social- había 25 productos y en las despensas 
llegaron ocho o siete..., era de esperarse cuando se veía cómo los funcionarios sacaban cosas de los costales y armaban sus propias despensas con lo que debería ir a las comunidades".

En todo caso, debido a la duración de las restricciones impuestas por el ayuntamiento municipal, las despensas entregadas no cubrieron las necesidades de cuetzaltecas y cuetzaltecos, que se vieron obligados a desobedecer las medidas de cierre de establecimientos y de la prohibición de ventas en vía pública.

\section{Conclusiones}

Las medidas adoptadas por la administración municipal limitaron progresivamente las actividades comerciales, con particular efecto en todos los servicios asociados al turismo, que es la principal fuente de ingreso económico para el municipio de Cuetzalan del Progreso. Sin embargo, su cumplimiento estricto únicamente se dio durante las primeras semanas, después no se acataron debido a la urgencia de los habitantes por obtener ingresos para satisfacer sus necesidades y las de sus familias.

Adicionalmente, se percibe por parte de los prestadores de servicios asociados al turismo que no hay diálogo con el ayuntamiento municipal, quien dictamina medidas que resultan ser ineficientes, dado que no tiene pleno conocimiento de las dinámicas específicas de este sector.

En suma, para un municipio rural con población mayoritariamente originaria que tiene niveles muy altos de marginación socioeconómica, las restricciones impuestas a causa de la pandemia causada por el COVID-19 y la falta de apoyos y garantías suficientes y contextualizadas que garanticen la satisfacción de las necesidades básicas de sus habitantes, tiene implicaciones profundas en su calidad de vida, haciendo imposible el cumplimiento cabal de los lineamientos formulados desde los niveles de gobierno.

\section{Referencias}

Agredo G. (2006). El territorio y su significado para los pueblos indígenas. Revista Luna Azul, 23, 28-32. https://www.redalyc.org/articulo.oa? id $=321727225006$

Alcívar, I., y Bravo, O. (2017). Turismo Sostenible: una alternativa de desarrollo comunitario desde un componente cultural. Espirales Revista Multidisciplinaria de Investigación, 1, 31-44.

Báez, L. (2004). Nahuas de la Sierra Norte de Puebla. En Pueblos indígenas del México contemporáneo (Primera ed). Comisión Nacional para el Desarrollo de los Pueblos Indígenas -CDI/ Programa de las Naciones Unidas para el Desarrollo -PNUD-. https://www.gob.mx/ cms/uploads/attachment/file/12557/nahuas_ sierra_norte_puebla.pdf

Bellota, L. Á. (2017). Programa de Pueblos Mágicos: valorización turistica de la cultura (No. 249; Documento de Trabajo). www.diputados. gob.mx/cesop

Brown, D. L., y Schafft, K. A. (2019). Rural people and communities in the 21st century. Resilience $y$ transformation (2da. ed.). Polity Press.

Bui, H. T., Jones, T. E., Weaver, D. B., y Le, A. (2020). The adaptive resilience of living cultural heritage in a tourism destination. Journal of Sustainable Tourism, 28(7), 1022-1040. https://doi. org/10.1080/09669582.2020.1717503

CEIGEP. (2021). Sistema estatal de información. Comité estatal de información estadistica $y$ geográfica del estado de Puebla. Fichas municipales en información estadística. http:// ceigep.puebla.gob.mx/informacion_basica_ municipio.php

Cheshire, L., Esparcia, J., y Shucksmith, M. (2015). Community resilience, social capital and territorial governance. Ager, 18, 7-38. https://doi. org/10.4422/ager.2015.08

Contreras O, R. (2000). Empoderamiento campesino y desarrollo local. Revista Austral de Ciencias Sociales, 4, 55-68. https://doi.org/10.4206/rev. austral.cienc.soc.2000.n4-03 
de Esteban Curiel, J., y Antonovica, A. (2018). El ecoturismo como modelo internacional de desarrollo sostenible del turismo cultural. Teoría y Praxis, 6(8), 43-53. https://doi.org/10.22403/ uqroomx/typ08/03

García González, E. D., y López Guevara, V. M. (2018). Propuesta de una agenda para la investigación del turismo sustentable en los pueblos mágicos de Puebla. Regiones y Desarrollo Sustentable, XVIII(34), 9-26.

Gobierno del Estado de Puebla. (2010). Programa de ordenamiento ecológico local del territorio del municipio de Cuetzalan del Progreso. http:// www.puebla.gob.mx/index.php/gobierno/ gobernador

Gobierno del Estado de Puebla. (2016). Plan de manejo en función del programa pueblos mágicos (p. 44). http://www.puebla.gob.mx/index.php/ gobierno/gobernador

González Álvarez, A. (2018). Koujpapataninij. La danza de los voladores, el tiempo y el territorio maseual. Anales de Antropología, 52(1), 85-88.

González Álvarez, A. (2020). Kaltaixtapeniloyan. Casa donde se abre el espiritu. Soñando el despertar del pueblo masewal. Universidad Autónoma Metropolitana, Unidad Xochimilco.

H. Ayuntamiento de Cuetzalan del Progreso Puebla. (2018). Programa municipal de desarrollo turístico Cuetzalan del Progreso.

H. Ayuntamiento de Cuetzalan del Progreso Puebla [AyuntamientoCuetzalanPuebla. Organización gubernamental]. (2020, 16 de marzo). Es momento de que tod@s pongamos nuestro granito de arena para evitar la propagación del COVID-19, te invitamos a seguir [Imagen adjunta] [Publicación de estado]. Facebook. https://www.facebook.com/AyuntamientoCuetzalanPuebla/posts/620716435144658

Henriques, J. M. (2016). Coesão territorial, resiliência e inovação social: o programa rede social. En IESE-Instituto de Estudos Sociais e Económicos (Ed.), Agricultura, floresta e desenvolvimiento rural (pp. 199-214).
Instituto Nacional de Estadística y Geografía -INEGI-. (2020a). Censos económicos 2019. Datos Abiertos. https://www.inegi.org.mx/ programas/ce/2019/\#Datos_abiertos

INEGI. (2020b). Marco Geoestadístico. Censo de Población y Vivienda 2020. Mapas. https:// www.inegi.org.mx/temas/mg/\#Descargas

Instituto de Geografía -Universidad Nacional Autónoma de México UNAM. (1992). Atlas Nacional de México 1990-1992. Hojas: I.11, IV.4.6, IV.4.8 y IV.4.10. https://geodigital.igg. unam.mx/atlas_nacional/index.html/\#tomoi

Instituto de Geografía -UNAM. (2007). Nuevo Atlas Nacional de México. Hojas: NA.II.1, NA.IV.5, NA.IV.13, NA.V.3 y NA.VI.1. http://www. igeograf.unam.mx/Geodig/nvo_atlas/index. $\mathrm{html} /$

International Work Group of Indigenous Affairs -IWGIA-. (2019). Informe de derechos de los pueblos indigenas a la autonomía y al autogobierno como manifestación del derecho a la libre determinación. https://www.iwgia.org/images/ documentos/Statements-support/Informe_ autonoma_ESP.pdf

Leff, E. (2000). Espacio, lugar y tiempo: la reapropiación social de la naturaleza y la construcción local de la racionalidad ambiental. Desenvolvimento e Meio Ambiente, 1, 57-69. https://doi.org/10.5380/dma.v1i0.3057

Leff, E. (2004). Racionalidad ambiental y diálogo de saberes. Significancia y sentido en la construcción de un futuro sustentable. Polis Revista Latinoamericana, 2(7). https://polis.revues.org/ 6232\#article-6232\%0A

Maldonado González, A. L., y González Gaudino, É. F. (2013). De la resiliencia comunitaria a la ciudadanía ambiental. El caso de tres localidades en Veracruz, México. Integra Educativa, $V I(3), 13-28$.

Morales Morales, H. F. (2006). Turismo comunitario: Una nueva alternativa de desarrollo indígena. AIBR. Revista de Antropología Iberoamericana, 1(2), 249-264. https://doi.org/10.11156/ aibr.010205 
Mosonyi, E. E. (2021). El despertar del mundo indígena: desde la invisibilidad a potenciales salvadores de la humanidad. Reflexiones en torno al cincuentenario de la exitosa "Declaración de Barbados." En A. Chirif (Ed.), Por la conquista de la autodeterminación (pp. 33-44). Grupo internacional de trabajo sobre asuntos indígenas -IWGIA-.

Orozco Alvarado, J., y Núnez Martínez, P. (2013). Las teorías del desarrollo. En el análisis del turismo sustentable. InterSedes: Revista de Las Sedes Regionales, XIV(27), 144-167. http:// www.redalyc.org/pdf/666/66622603005.pdf

Parlamento Andino. (2019, November). Hilando el sur: imagen, hilo y palabra. El Cóndor, 84, 38-39. www.parlamentoandino.org
Secretaría de Salud. (2020). Información referente a casos COVID-19 en México. Datos Abiertos. Gobierno de México. https://datos.gob.mx/ busca/dataset/informacion-referente-a-casos-covid-19-en-mexico

Tauli-Corpuz, V. (2020). El derecho de los pueblos indígenas a la libre determinación por medio de la autonomía o el autogobierno. En A. Parellada, L. García-Alix, y J. Dahl (Eds.), Construyendo autonomías (Primera ed, pp. 13-16). 